\title{
Improved in vitro rooting of Prunus dulcis Mill. cultivars
}

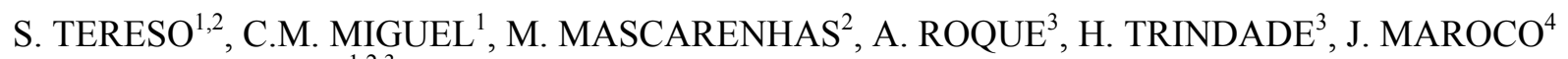 \\ and M.M. OLIVEIRA ${ }^{1,2,3 *}$
}

Forest Biotech Lab, IBET/ITQB, Quinta do Marquês, 2784-505 Oeiras, Portugal ${ }^{1}$

EGP Lab,ITQB/IBET, Quinta do Marquês, 2784-505 Oeiras, Portugal ${ }^{2}$

Univ. Lisboa, Fac. Ciências, Ed. C2, Piso 1, Campo Grande, 1749-016 Lisboa, Portugal ${ }^{3}$

Grupo de Estatística e Matemática, ISPA, Rua Jardim do Tabaco 34, 1149-041 Lisboa, Portugal ${ }^{4}$

\begin{abstract}
A highly reproducible system was developed for efficient rooting of cultivars Boa Casta (BC) and Peneda and a BC seedling-derived clone (BC VII) of almond (Prunus dulcis Mill.). Twenty-four accessions derived from the clone $\mathrm{BC}$ VII and subjected to various in vitro culture treatments were screened. The long induction pre-treatment (LIP, $5 \mathrm{~d}$ ), the brief induction pre-treatment (BIP, $16 \mathrm{~h}$ ) and the hormonal shock by short dipping in hormone solution (1 min), were tested. BIP was the only that allowed rooting of cultivars. In BC VII, it induced high rooting frequencies (47 - $100 \%$ ) when using a solution of $0.4 \mathrm{mM}$ indole-3-butyric acid solidified with $2 \mathrm{~g} \mathrm{dm}^{-3}$ gellam gum for 16-h. The response to the auxin type was variable depending on the cultivar and the root induction pre-treatment used. Root number was significantly different between the two cultivars and BC VII. Root length was significantly higher when using $0.005 \mathrm{mM}$ IBA in LIP but this concentration induced apical necrosis. The improved acclimatization procedure for up to 4 weeks increased the survival to $45 \%$. The initiation and development of adventitious roots were proved to be asynchronous.
\end{abstract}

Additional key words: adventitious root, indole-3-acetic acid, indole-3-butyric acid, mother plant age.

\section{Introduction}

Many woody species are difficult to root through cuttings after the seedling-derived stage. Almond (Prunus dulcis Mill.) is particularly difficult to root both in vivo and in vitro. In vitro rooting of this species is strongly genotype-dependent and successful only for some cultivars (Rugini 1983, 1987, Rugini and Verma 1983, Caboni and Damiano 1994, Caboni et al. 1997, Miguel 1998, Ainsley et al. 2001), while others only root after genetic transformation (Damiano et al. 1995). The long induction pre-treatment (LIP) with auxins was shown to be crucial for the rooting of other Rosaceae, namely rose and apple (Collet and Lê 1987) and some almond cultivars (Rugini and Verma 1983, Caboni and Damiano 1994, Caboni et al. 1997), whereas for others, brief induction pre-treatment (BIP) for $11-16 \mathrm{~h}$ was more effective (Rugini et al. 1997, Miguel 1998, Tereso 1999, Ainsley et al. 2001). The duration of auxin treatment can be a critical factor, since auxin is required for the induction of root primordia but it is often inhibitory for root growth at a later stage (De Klerk et al. 1999). The choice of the auxin type and concentration can differ according to the specific culture conditions involved. The rooting of some woody species including Prunus can be also improved under darkness during the first week (Sriskandarajah et al. 1982, Rugini et al. 1993, Caboni et al. 1997).

The main objective of this paper was to find a reproducible method for the successful rooting of Portuguese almond genotypes derived from a wide range of different in vitro culture treatments. We tested the effects of the induction pre-treatment, the auxin type and concentration, and mother-plant age on rooting of in vitro shoots of two almond cultivars.

Received 14 December 2006, accepted 11 June 2007.

Abbreviations: BC - cv. Boa Casta; BIP - brief induction pre-treatment; 2,4-D - 2,4-dichlorophenoxyacetic acid; IAA - indole-3acetic acid; IBA - indole-3-butyric acid; LIP - long induction pre-treatment; TDZ - thidiazuron.

Acknowledgments: This research was supported by Fundação para a Ciência e Tecnologia (FCT) and the III Framework Programme of the European Community, through PhD grant SFRH/BD/1186/2000 to S Tereso and Post-Doc grant SFRH/ BPD/ $17902 / 2004$ to C Miguel. Research was supported by PRAXIS XXI - 3/3.2/ HORT/ 2143/95 and Centro de Biotecnologia Vegetal of IBQF.

* Corresponding author; fax: (+351) 214421161, e-mail: mmolive@itqb.unl.pt 


\section{Materials and methods}

Culture establishment: In vitro cultures were established from explants of 30-year-old trees of almond (Prunus dulcis Mill.) cultivars Boa Casta (BC) and Peneda and maintained with 21-d sub-cultures on Murashige and Skoog (1962; MS) medium supplemented with $3.55 \mu \mathrm{M}$ 6-benzylaminopurine (BAP) and $0.049 \mu \mathrm{M}$ indole-3-butyric acid (IBA) (MA medium), as described by Miguel et al. (1996).

Shoots from BC clone VII (BC VII) were obtained by in vitro axillary shoot multiplication of a seedling-derived almond plantlet from open-pollinated cultivar BC. Shoots were maintained with 21-d sub-cultures on MS medium supplemented with $1.33 \mu \mathrm{M}$ BAP and $0.049 \mu \mathrm{M}$ IBA. Shoots from BC VII were submitted to either genetic transformation, adventitious shoot regeneration or to various treatments for virus-elimination (Raquel 1998, Tereso 1999). For adventitious shoot regeneration young leaves were excised from in vitro grown plantlets and cultivated on MS basal medium supplemented with $1.5 \mathrm{mg} \mathrm{dm}^{-3}$ thidiazuron (TDZ), $0.5 \mathrm{mg} \mathrm{dm}^{-3}$ indole-3acetic acid (IAA), $0.01 \mathrm{mg} \mathrm{dm}^{-3}$ 2,4-dichlorophenoxyacetic acid (2,4-D), $30 \mathrm{~g} \mathrm{dm}^{-3}$ sucrose, and $5 \mathrm{~g} \mathrm{dm}^{-3}$ Gelrite, $\mathrm{pH} 5.8$ ) in darkness for $21 \mathrm{~d}$, followed by transfer to elongation medium (identical to the induction medium but with $1.0 \mathrm{mg} \mathrm{dm}^{-3}$ BAP instead of TDZ, IAA and 2,4-D) until shoots could be excised and transferred to micropropagation medium.

The transformation conditions (Miguel and Oliveira 1999) included a pre-culture period of $3 \mathrm{~d}$ in dark, followed by wounding with a scalpel dipped in bacterial suspension (Agrobacterium EHA105/p35SGUSINT). After 3-d co-cultivation, the explants were transferred to fresh MS medium supplemented with $300 \mathrm{mg} \mathrm{dm}^{-3}$ cefotaxime and $15 \mathrm{mg} \mathrm{dm}^{-3}$ kanamycin. After $21 \mathrm{~d}$ of induction in darkness, the explants were transferred to elongation medium as above, but with $200 \mathrm{mg} \mathrm{dm}^{-3}$ cefotaxime and $50 \mathrm{mg} \mathrm{dm}^{-3}$ kanamycin. After 3 weeks in elongation, the shoots were transferred to micropropagation medium with the same concentration of cefotaxime, but with kanamycin reduced to $30 \mathrm{mg} \mathrm{dm}^{-3}$. After two sub-cultures in these conditions, the surviving shoots were transferred to kanamycin-free medium, and two months later cefotaxime was also removed.

The virus elimination protocols used thermotherapy and/or chemotherapy. Chemotherapy treatments were performed using $10 \mathrm{mg} \mathrm{dm}^{-3}$ of Isoprinosine (purine analog) or Trifluorotimidine (pirimidine analog), for $60 \mathrm{~d}$ with sub-cultures on fresh medium every $20 \mathrm{~d}$. After the treatment, the shoot apex was isolated and transferred to fresh MS medium. In chemotherapy coupled with thermotherapy, the same protocol was applied, but in the first $20 \mathrm{~d}$ the $16-\mathrm{h}$ photoperiod with a temperature of $35 \pm 2{ }^{\circ} \mathrm{C}$ was followed by 8 -h dark at $25 \pm 2{ }^{\circ} \mathrm{C}$.

In all other cases, the cultures were maintained in a growth chamber at $22 \pm 2{ }^{\circ} \mathrm{C}$ under a 16-h photoperiod with irradiance of $35 \mu \mathrm{mol} \mathrm{m} \mathrm{m}^{-2} \mathrm{~s}^{-1}$ provided by white fluorescent lamps.
Rooting: Rooting of in vitro shoots established from cvs. Peneda and $\mathrm{BC}$ after 1 or 2 years continued subculturing and from clone BC VII maintained in vitro for 5 years was studied. The shoots were submitted to two different pre-treatments, BIP and LIP, modified from Collet and Lê (1987), as described by Miguel (1998). In the BIP method, shoot basal ends were dipped in an autoclaved solution of $0.9 \mathrm{mM}$ IBA or IAA ( $\mathrm{pH} 5.8$ ) solidified with $2 \mathrm{~g} \mathrm{dm}^{-3}$ gellam gum for $16-\mathrm{h}$. Shoots were then transferred to hormone-free medium (halfstrength MS macro and micronutrients, MS vitamins, $20 \mathrm{~g} \mathrm{dm}^{-3}$ sucrose and $2 \mathrm{~g} \mathrm{dm}^{-3}$ gellam gum) for $7 \mathrm{~d}$, followed by transfer to the same medium solidified with $7 \mathrm{~g} \mathrm{dm}^{-3}$ agar. In the LIP method, shoots were placed for $7 \mathrm{~d}$ on half strength MS macro and micronutrients supplemented with $0.005 \mathrm{mM}$ IBA or IAA, $20 \mathrm{~g} \mathrm{dm}^{-3}$ sucrose, and $7 \mathrm{~g} \mathrm{dm}^{-3}$ agar, in the dark. Shoots were then transferred to the photoperiod described above and subcultured on the same medium without plant growth regulators (PGR).

BC VII shoots were used to compare 9 treatments based on LIP, BIP or "hormone shock" pre-treatments, as described by Tereso (1999). LIP involved 5-d induction on the medium described above but with $0.005 \mathrm{mM}$ of IAA $\left(\mathrm{T}_{1}\right)$ or IBA $\left(\mathrm{T}_{2}\right)$, or $0.01 \mathrm{mM}$ IBA $\left(\mathrm{T}_{3}\right)$ as PGR. In $\mathrm{BIP}$, we tested a 16-h induction with an autoclaved solution $(\mathrm{pH} 5.8)$ of $0.4 \mathrm{mM}$ IAA $\left(\mathrm{T}_{4}\right)$ or $0.9 \mathrm{mM}$ IAA $\left(\mathrm{T}_{5}\right)$, or $0.4 \mathrm{mM}$ IBA $\left(\mathrm{T}_{6}\right)$ or $0.9 \mathrm{mM}$ IBA $\left(\mathrm{T}_{7}\right)$ solidified with $2 \mathrm{~g} \mathrm{dm}^{-3}$ gellam gum. The "hormone shock" pretreatment involved a $1 \mathrm{~min}$ dipping in an autoclaved solution ( $\mathrm{pH} 5.8$ ) of $5 \mathrm{mM}$ of IAA $\left(\mathrm{T}_{8}\right)$ or IBA $\left(\mathrm{T}_{9}\right)$. After LIP and "hormone shock" pre-treatments performed in darkness, shoots were transferred to photoperiod and subcultured on hormone-free medium consisting of halfstrength MS macro and micronutrients and MS vitamins with $20 \mathrm{~g} \mathrm{dm}^{-3}$ sucrose 20 (pH 5.8) and $7 \mathrm{~g} \mathrm{dm}^{-3}$ agar (root development medium). After BIP, for the first 7 days of culture on root development medium, $2 \mathrm{~g} \mathrm{dm}^{-3}$ gellam gum was used instead of agar.

In another experiment, BC VII shoot cultures previously submitted to genetic transformation (BC VII-T) (Miguel and Oliveira 1999) or to thermotherapy for virus elimination (BC VII-S) (Raquel 1998) were compared regarding their response to the type of gelling agent in root development medium $\left(7 \mathrm{~g} \mathrm{dm}^{-3}\right.$ agar or $2 \mathrm{~g} \mathrm{dm}^{-3}$ gellam gum) following 16-h induction with $0.4 \mathrm{mM}$ IBA $\left(\mathrm{T}_{6}\right)$.

The root induction percentage and the number of roots per rooted shoot were recorded one month after the beginning of the auxin treatments.

Further, a large-scale study was conducted in which IBA was tested at concentrations 0.4 or $0.005 \mathrm{mM}$ on groups of BC VII shoots previously submitted to different in vitro culture treatments. The in vitro treatments were genetic transformation (BC VII-T), adventitious regeneration (group 1) or virus eradication (groups 2 to 23). Thirty shoots per group were used for each treatment. The root induction percentage, the number of 
roots per rooted shoot, the average root length and the frequency of apical necrosis were recorded one month after the beginning of the auxin treatment.

Acclimatization: All the rooted plantlets were transferred to peat and sand $(1: 1)$ and acclimatised in a growth chamber by gradually decreasing the relative humidity $(\mathrm{RH})$ from 95 to $80 \%$ over a 3 -d period and then transferred to the greenhouse. Concerning to the rooted plantlets previously recovered from in vitro treatment programs, 42 plantlets from BC VII-T and 35 plantlets from BC VII-S were pre-acclimatised in axenic conditions for three to four weeks, using autoclaved peat and sand (1:1) supplemented with MS solution, in the growth chamber under the conditions described above. During acclimatisation, plantlets were transferred to a similar fresh autoclaved mixture and $\mathrm{RH}$ was decreased from 95 to $45 \%$. After $28 \mathrm{~d}$, the surviving plantlets were transferred to the greenhouse.

Histology of adventitious roots: Histological characterization of some stages of auxin induction of almond rhizogenesis was performed. Samples from the base of the transformed plantlets were collected $15 \mathrm{~d}$ after the beginning of the auxin treatment. Samples from plantlets rooted using 0.005 or $0.4 \mathrm{mM}$ IBA were collected from isolated roots along $10 \mathrm{~d}$ after hormonal induction. Tissues were fixed and sectioned following the procedure described by Silva et al. (2003) for almond shoots. A general staining was performed by toluidine blue (Feder and O'Brien, 1968) for $5 \mathrm{~min}$ at $55^{\circ} \mathrm{C}$ followed by washing with water and drying. Stained sections were examined under a light microscope (Nikon Eclipse TE 300, Japan).

Statistical analysis: Data was $\arcsin ($ Sqrt) and/or $\ln$ transformed as required to validate $A N O V A$ assumptions, namely normality of data distributions and homoscedasticity of variances. Data for rooting percentages were dummy coded and analyzed by $A N O V A$. Individual treatment differences were evaluated with Tukey's HSD and non-parametric multiple median comparisons. For the incomplete designs, a Linear Mixed Model was used to test for significance of main effects and interactions between factors. Rooting percentages per medium and per plant material were compared with Z-tests for the difference of proportions. Statistical analysis was performed with SPSS (v. 12, SPSS Inc, Chicago), and significant effects were accepted for $P<0.05$. Concerning the root number per rooted shoot, data were analyzed by the non parametric Kruskal-Wallis ANOVA on ranks followed by multiple mean rank comparisons.

\section{Results and discussion}

Rooting of cvs. Peneda and BC shoots established after either 1 or 2 years in vitro sub-culturing and from clone BC VII was compared. Root induction frequency was not significantly different between $\mathrm{BC}$ and Peneda (Fig. 1A). IAA induced a significantly higher rooting frequency in $\mathrm{BC}$ and Peneda shoots but not in BC VII shoots. A significantly higher rooting was observed in BC VII as compared to 2 year in vitro grown $\mathrm{BC}$. By the LIP method, no rooting was observed in $\mathrm{BC}$ and Peneda

shoots, while in BC VII shoots one rooted shoot was observed after IBA treatment. The BIP method was more effective, promoting rooting in both $\mathrm{BC}$ and $\mathrm{BC}$ VII. Root number per rooted shoot was different between $B C$ and Peneda when IBA was used as PGR and between $\mathrm{BC}$ VII and $\mathrm{BC}$ (Fig. 1B). IBA induced a slightly higher root number on $\mathrm{BC}$ VII but not on $\mathrm{BC}$ or Peneda, when compared with IAA.

In various almond cultivars, IBA has been

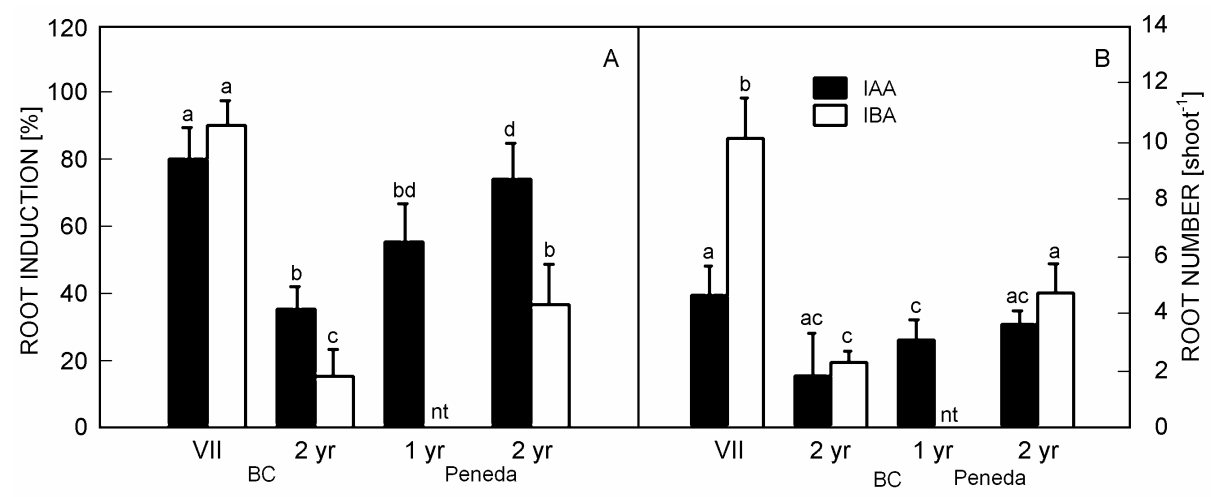

Fig. 1. Root induction $(A)$ and root number $(B)$ in seedling-derived BC VII shoots and of 1-year-old cv. Peneda or 2-year-old BC and Peneda in in vitro cultures. Twenty replicates were used per treatment. Means followed by different letter suffixes are significantly different as evaluated by Tukey-b's HSD tests. $\mathrm{nt}=$ non tested. $A$ ) $\mathrm{BC} v s$ Peneda: $F_{1.136}=0.000, P=0.986$; IAA $v s$ IBA: $F_{(1,131)}=5.078, P=0.026$; explant age: $F_{1.131}=19.633, P<0.001$; interaction auxin type $v$ s explant age: $F_{1.131}=2.343, P=0.128$. $B$ ) BC vs Peneda: $F_{1.77}=6.787, P=0.011$; explant age: $F_{2.72}=5.917, P=0.004$; IAA $v s$ IBA: $F_{1.72}=3.316, P=0.073$; the two-way interactions were not significant, $P>0.10$ ). 
recommended for root induction (Rugini and Verma 1983, Caboni et al. 1997, Tereso 1999). However, the appropriate auxin can depend on the almond genotype (Caboni and Damiano 1994), as we also found this in our study. The differences in effectiveness among auxins may be related to the different affinity of each auxin to the auxin receptor involved in the rooting process (Libbenga and Mennes 1995), which could be specific for each cultivar, or to different rates of auxin turnover. Our study compared for the first time the rooting ability of an almond cultivar versus seedling-derived material obtained from the same cultivar. The results indicated that there were significant differences when comparing effects of IAA with IBA and the age of the in vitro culture.

Rooting treatments based on LIP, BIP or "hormone shock" pre-treatments were compared using BC VII shoots. The response to the auxin type was variable depending on the root induction treatment $\left(T_{1}-T_{9}\right)$ used. In BC VII, the BIP method produced a significantly higher rooting frequency only when $0.4 \mathrm{mM}$ IBA was used (Fig. 2A) and a significantly higher root number using BIP with IBA as compared to LIP method (Fig. 2B). Regarding the root length, differences among treatments were only marginally significant (Fig. 2C).

The "hormone shock" pre-treatment was compared to BIP and LIP for the first time in almond by Tereso (1998), showing similar or lower rooting frequency and root number than BIP and LIP in cv. BC. In cv. Ne Plus Ultra, BIP showed better performance than "hormone shock" pre-treatment (Ainsley et al. 2001). Regarding the average root length, there were only marginal differences between treatments with no relation to the pre-induction method used (Fig. 2C). In Malus domestica (Jásik and De Klerk 1997), shoots did not show their maximum sensitivity to the auxin in the first $24 \mathrm{~h}$ after excision of shoot basal end. In our study, the increase of $16 \mathrm{~h}$ to $24 \mathrm{~h}$ in $\mathrm{T}_{6}$ treatment decreased the response to the auxin stimulus (data not shown).

The effects the type of gelling agent used in root development medium and of the IBA concentration in root induction medium in BC VII shoot cultures, when previously submitted to different in vitro treatments, were tested. When using BIP method with $0.4 \mathrm{mM}$ IBA and agar or gellam gum as solidifying agents, rooting frequency was identical $(60 \% ; Z=0.18 ; P=0.86$; BC VII-T vs BC VII-S, $Z=2.19, P=0.014$ ) and root number variations were also not significant $(4-9$ roots per rooted shoot; $F_{1,40}=0.875, P=0.355$; BC VII-T $v s$ BC VII-S, $\left.F_{1,40}=0.079, P=0.780\right)$.

The use of gellam gum induced higher regeneration rates than agar in M. domestica (De Bondt et al. 1996). In almond, agar is commonly used (Rugini and Verma 1983, Caboni and Damiano 1994, Caboni et al. 1997, Ainsley et al. 2001). However, in our study, the gelling agent did not affect rooting performance of this species.

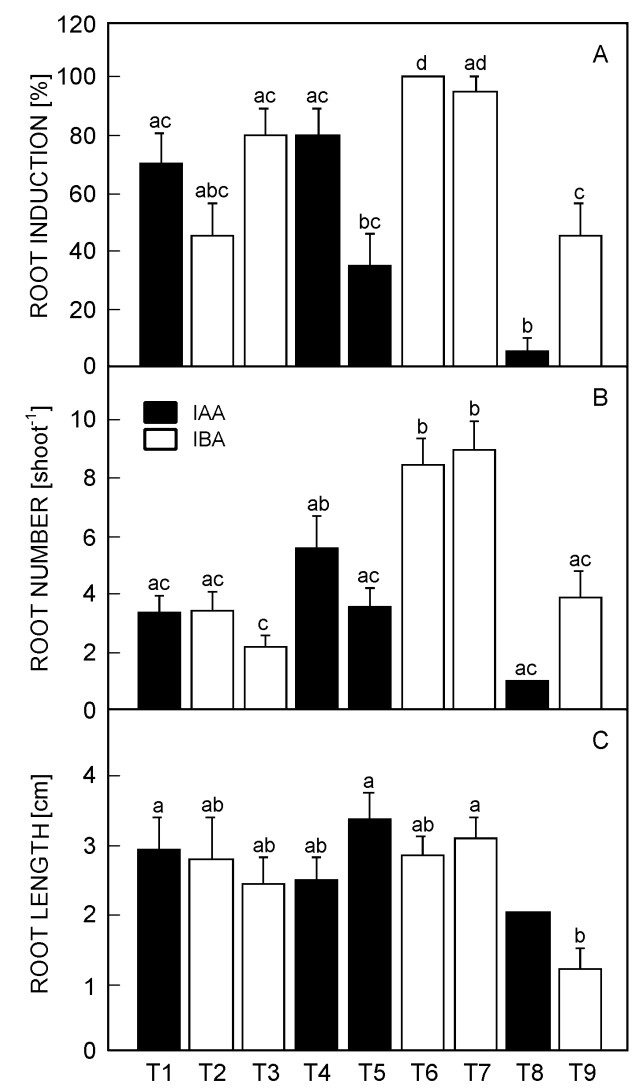

Fig. 2. Rooting of BC VII shoots by treatments $T_{1}$ to $T_{9}$. Twenty replicates were used per treatment. Means with different letter are significantly different according to the Tukey-b's HSD tests. A - Root induction; $F_{8.171}=12.373, P<0.001$. $B$ - Number of roots induced per rooted shoot; $F_{8.102}=1.894, P=0.069$ ). $C$ - Root length per rooted shoot; $F_{8.102}=1.894, P=0.069$.

Shoots from BC VII-S showed a significantly higher rooting percentage $(90 \%)$ than BC VII-T $(85 \%)$. Shoots from BC VII-T were obtained by adventitious shoot regeneration from Agrobacterium-mediated transformation of leaf explants (Miguel and Oliveira 1999). This process involved the exposure to high concentrations of PGR, which in some cases can change the nuclear DNA methylation level and thereby the gene expression (Litz 1993). Although BC VII-S and BC VII-T shoots derived from the same genotype, the respective in vitro culture pre-treatments may explain the differences in rooting

Fig. 3. Rooting of BC VII shoot groups coming from 23 different in vitro culture treatments, thereafter induced by $0.4 \mathrm{mM}$ or $0.005 \mathrm{mM}$ IBA. Group 1 was only submitted to $0.4 \mathrm{mM}$ IBA treatment. Thirty replicates were used per treatment. $A-$ IBA $0.005 v s$ $0.4 \mathrm{mM}: F_{1.1311}=1089.33 ; P<0.001$; shoot group differences at $0.005 \mathrm{mM}$ IBA: $F_{22.654}=4.906, P<0.001$; shoot group differences at $0.4 \mathrm{mM}$ IBA: $F_{22.613}=56.186, P<0.001 . B-$ IBA 0.005 vs $0.4 \mathrm{mM}: H_{1}=147.141, P=0.001$; shoot group differences at IBA $0.005 \mathrm{mM}: H_{22}=20.538, P=0.083$; shoot group differences at IBA $0.4 \mathrm{mM}: H_{22}=22.515, P=0.430$. $C-$ IBA $0.005 v s 0.4 \mathrm{mM}$ : $H_{1}=37.35, P<0.001$; shoot group differences at IBA $0.005 \mathrm{mM}: H_{18}=20.03, P=0.331$; shoot group differences at IBA $0.4 \mathrm{mM}$ : $H_{22}=125.31, P<0.001$. D - IBA 0.005 vs $0.4 \mathrm{mM}: F_{1.1311}=4923.4, P<0.001$; shoot group differences at $0.005 \mathrm{mM}$ IBA: $F_{22.654}=5.448, P<0.001$; shoot group differences at $0.4 \mathrm{mM}$ IBA: $F_{22.613}=0.974, P=0.496$. 

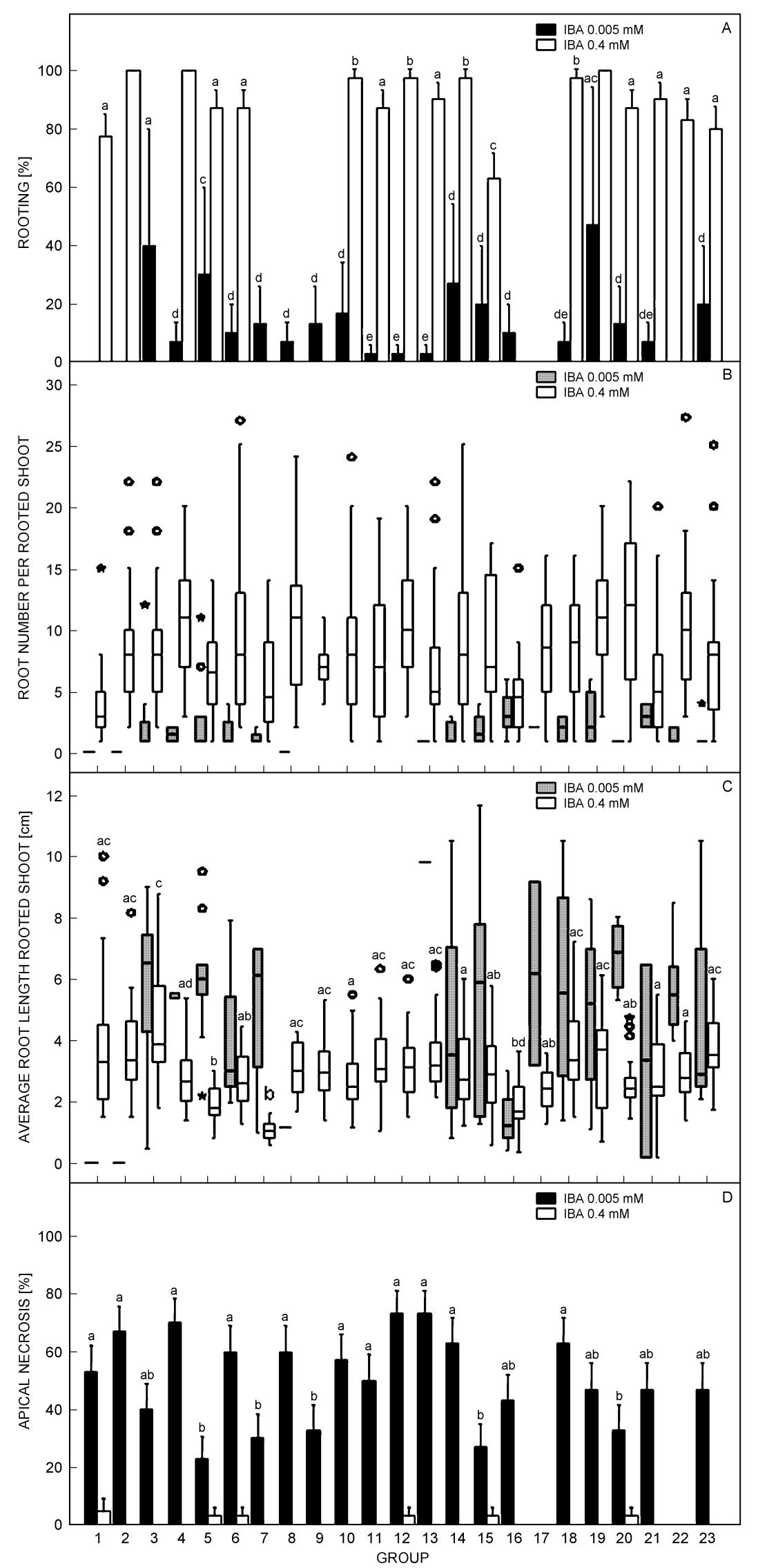

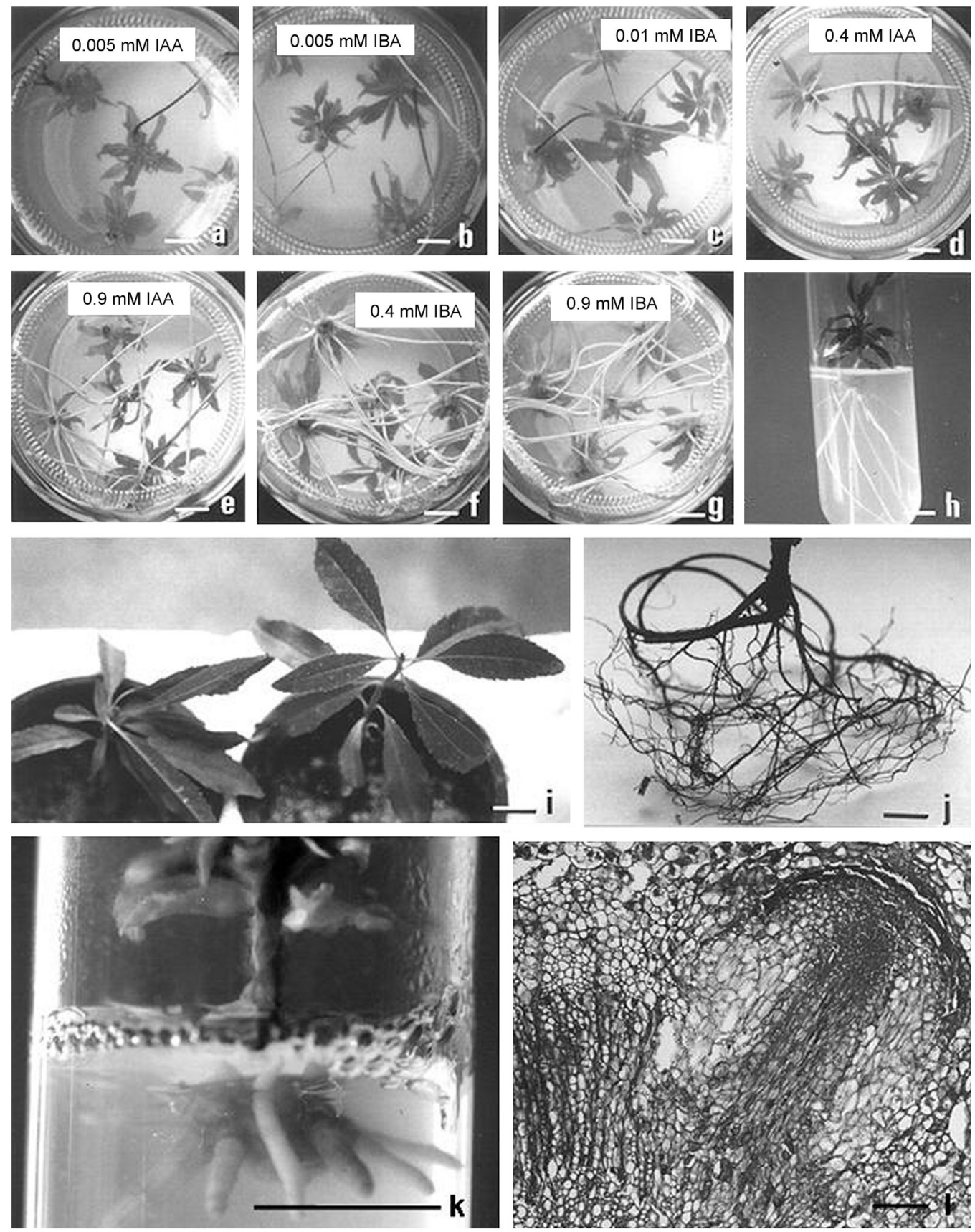

Fig. 4. Rooting of BC VII shoots. $a$ to $g$ - aspects of roots $30 \mathrm{~d}$ after treatment using the LIP $(a-c)$, or the BIP $(d-g)$ methods $\left(a-\mathrm{T}_{1}\right.$, $\left.b-\mathrm{T}_{2}, c-\mathrm{T}_{3}, d-\mathrm{T}_{4}, e-\mathrm{T}_{5}, f-\mathrm{T}_{6}, \mathrm{~g}-\mathrm{T}_{7}\right) ; h$ - shoot recovered from a virus eradication program and rooted in $\mathrm{T}_{6}$ conditions; $i$ - acclimatised plantlets derived from treatment $\mathrm{T}_{6} ; j$ - aspect of the root system produced after 2 months in soil; $k$ - aspect of roots from a transformed plantlet $30 \mathrm{~d}$ after treatment using $\mathrm{T}_{6}$ treatment; $l$ - transversal section from a root primordium. Bars $a-k=1 \mathrm{~cm}$; $l=100 \mu \mathrm{m}$.

ability. When comparing the 23 shoot groups coming from 23 in vitro culture treatments, significant differences in the root induction frequency were observed (Fig. $3 A$ ). When comparing histological sections from roots obtained with IBA 0.005 or $0.4 \mathrm{mM}$, no morphological differences were detected. Rooting percentage significantly increased when using IBA at $0.4 \mathrm{mM}$
$(47-100 \%)$ as compared to $0.005 \mathrm{mM}(0-47 \%)$ (Fig. 3A). The IBA concentration $0.4 \mathrm{mM}$ induced also significantly higher root numbers (Fig. $3 B$ ) as compared to $0.005 \mathrm{mM}$. No significant differences were observed in root numbers among shoot groups (Fig. 3B). In the majority of the shoot groups tested, $0.005 \mathrm{mM}$ IBA induced a significantly higher root length as compared to 
$0.4 \mathrm{mM}$ (Fig. 3C). Root length and apical necrosis differed significantly among shoot groups only when using $0.4 \mathrm{mM}$ IBA (Fig. $3 C, D$ ). Opposite to what was expected, the lower auxin concentration $(0.005 \mathrm{mM})$ caused higher apical necrosis than $0.4 \mathrm{mM}$ IBA (Fig. 3D). In walnut, apical necrosis has been associated to a high sensitivity to IBA during root induction, possibly by the oxidation of phenolic compounds (El Euch et al. 1998). In Prunus armeniaca, apical necrosis on rooting has been prevented by using the auxin at low concentration (Murai et al. 1997) or at high concentration for a short period of time (Pérez-Tornero and Burgos 2000). In almond cv. Nonpareil, 1.0 mM IBA induced higher rooting frequencies than $0.5 \mathrm{mM}$ (Ainsley et al. 2001) but no other parameters were compared. In our study, the use of $0.8 \mathrm{mM}$ IBA instead of $0.4 \mathrm{mM}$ in cultivar $\mathrm{BC}$ induced no relevant differences in the rooting frequency, root number and root length (data not shown). Our results suggest that $0.4 \mathrm{mM}$ IBA might be the lower concentration effective for root induction and plant survival. IBA at $0.005 \mathrm{mM}$ might be too low to guarantee plant response and survival and reproducible results.

When the acclimatisation was performed by direct transfer of the in vitro rooted shoots (Fig. 4) to the

\section{References}

Ainsley, P.J., Collins, G.G., Sedgley, M.: In vitro rooting of almond (Prunus dulcis Mill.). - In Vitro cell. dev. Biol. Plant. 37: 778-785, 2001.

Caboni, E., Damiano, C.: Rooting in vitro two almond genotypes. - Plant Sci. 96: 163-165, 1994.

Caboni, E., Tonelli, M.G., Lauri, P., Kevers, C., Damiano, C., Gaspar, T.: Biochemical aspects of almond microcuttings related to in vitro rooting ability. - Biol. Plant. 39: 91-97, 1997.

Collet, G.F., Lê, C.L.: Role of auxin during in vitro rhizogenesis of rose and apple-trees. - Acta Hort. 212: 273-280, 1987.

Damiano, C., Archilletti, T., Caboni, E., Lauri, P., Falasca, G., Mariotti, D., Ferraiolo, G.: Agrobacterium-mediated transformation of almond: in vitro rooting through localized infection of $A$. rhizogenes W. T. - Acta Hort. 392: 161-169, 1995.

De Klerk, G., Van der Krieken, W., De Jong, J.C.: The formation of adventitious roots: new concepts, new possibilities. - In Vitro cell. dev. Biol. Plant. 35: 189-199, 1999.

De Bondt, A., Eggermont, K., Penninckx, I., Goderis, I., Broeckaert, W.F.: Agrobacterium-mediated transformation of apple (Malus domestica Borkh.): an assessment of factors affecting regeneration of transgenic plants. - Plant Cell Rep. 15: 549-554, 1996

Druart, P.: In vitro culture and micropropagation of plum (Prunus spp.). - In: Bajaj, Y.P.S. (ed.): Biotechnology in Agriculture and Forestry. Vol 18. Pp. 278-303. SpringerVerlag, Berlin - Heidelberg 1992.

El Euch, C., Jay-Allemand, C., Pastuglia, M., Doumas, P., Charpentier, J.P., Capella, P., Jouanin, L.: Expression of antisense chalcone synthase RNA in transgenic hybrid walnut microcuttings. Effect on flavonoid content and rooting ability. - Plant mol. Biol. 38: 467-479, 1998. ex vitro conditions, only a few plantlets were successfully acclimatised. When axenic conditions were used in the first three to four weeks of acclimatisation, its success increased up to $45 \%$, suggesting the usefulness of these conditions in future experiments.

Plantlets rooted using the selected treatment $\mathrm{T}_{6}$ (16-h induction with $0.4 \mathrm{mM}$ IBA solidified with $2 \mathrm{~g} \mathrm{dm}^{-3}$ gellam gum) and successfully acclimatised produced a strong root system (Fig. 4i,j). Roots induced in BC VII-S shoots were longer and less thick than those of BC VII-T (Fig. 4k), which may be eventually related to their higher survival during acclimatization (45\% in non-transformed plantlets compared with $2 \%$ in transformed plantlets). For the first time the hormonal induction of almond rhizogenesis was studied through the histological characterization of the different phases of this process. Histological sections made from transformed plantlets showed anatomical changes typical from other woody species. However, $15 \mathrm{~d}$ after root induction, root primordia together with meristemoids in different development stages were present (Fig. 4k). These results showed that the initiation and development of adventitious roots were asynchronous in this species.

Feder, N., O'Brien, T.P.: Plant microtechnique: some principles and new methods. - Amer. J. Bot. 55: 123-142, 1968.

Jásik, J., De Klerk, G.J.: Anatomical and ultrastructural examination of adventitious root formation in stem slices of apple. - Biol. Plant. 39: 79-90, 1997.

Libbenga, K.R., Mennes, A.M.: Hormone binding and signal transduction. - In: Davies, P.J. (ed.): Plant Hormones. Pp. 272-297. Kluwer Academic Publishers, Dordrecht 1995.

Litz, R.E.: Organogenesis and somatic embryogenesis. - Acta Hort. 336: 199-205, 1993.

Miguel, C.M.: Adventitious regeneration and genetic transformation of almond (Prunus dulcis Mill.). - PhD Thesis, Faculdade de Ciências, Univ. Lisboa, Lisboa 1998.

Miguel, C.M., Druart, P., Oliveira, M.M.: Shoot regeneration from adventitious shoots induced on seedling-derived and cultivar almond (Prunus dulcis Mill.) explants. - In Vitro cell. dev. Biol. Plant. 32: 148-153, 1996.

Miguel, C.M., Oliveira, M.M.: Transgenic almond (Prunus dulcis Mill.) plants obtained by Agrobacterium-mediated transformation of leaf explants. - Plant Cell Rep. 18: 387393, 1999.

Murai, Y., Harada, H., Yamashita, H.: In vitro propagation of apricot (Prunus armeniaca L.) cv. Bakuoh junkyou. - J. jap. Soc. hort. Sci. 66: 475-480, 1997.

Murashige, T., Skoog, F.: A revised medium for rapid growth and bioassays with tobacco tissue cultures. - Physiol. Plant. 15: 473-497, 1962.

Neves, C.: [Estudo de marcadores bioquímicos e celulares da rizogénese adventícia em sobreiro e videira micropropagados.] PhD. Thesis, Instituto Superior de Agronomia, Univ. Técnica Lisboa, Lisboa 2000. [In Portuguese.].

Pérez-Tornero, O., Burgos, L.: Different media requirements for micropropagation of apricot cultivars. - Plant Cell Tissue Organ Cult. 63: 133-141, 2000. 
Raquel, M.H.T.: [Diagnose de infecções virais, saneamento de cultivares portuguesas de amendoeira e pesquisa de estratégias para introdução de resistência a vírus.] - M.Sc. Thesis, Faculdade de Ciências, Univ. Lisboa, Lisboa 1998. [In Portuguese.]

Rugini, E.: Almond. - In: Evans, D.A., Sharp, W.R., Ammirato, P.V. (ed.): Handbook of Plant Cell Culture. Vol. IV. Pp. 574-611. Academic Press, New York 1983.

Rugini, E. Almond. - In: Vasil, I.K. (ed.): Cell Culture and Somatic Cell Genetics. Vol. IV. Pp 574-611. Academic Press, New York 1987.

Rugini, E., Jacoboni, A., Luppino, M.: Role of basal shoot darkening and exogenous putrescine treatments on in vitro rooting and on endogenous polyamine changes in difficultto-root woody species. - Scientia Hort. 53: 63-72, 1993.
Rugini, E., Verma, D.C.: Micropropagation of difficult-topropagate almond $(P$. amygdalus Batsch) cultivar. - Plant Sci. Lett. 28: 273-281, 1983

Silva, C., Tereso, S., Nolasco, G., Oliveira, M.M.: Cellular localization of prune dwarf virus in almond sections by in situ reverse transcription-polymerase chain reaction. Phytopathology 93: 278-285, 2003.

Sriskandarajah, S., Mullins, M.G., Nair, Y.: Induction of adventitious rooting in vitro difficult-to-propagate cultivars of apple. - Plant Sci. Lett. 24:1-9, 1982.

Tereso, S.: [Estudos de saneamento de viroses e de detecção do ilarvírus prune dwarf virus em amendoeira e introdução à técnica de trascrição inversa - polymerase chain reaction in situ.] - M.Sc. Thesis, Univ. Évora., Évora 1999. [In Portuguese.] 